\title{
Reflections
}

\section{Future as an object of governance - commentary to Jones}

\author{
JUHO LUUKKONEN
}

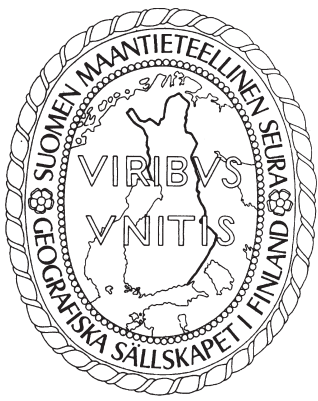

Luukkonen, J. (2019) Future as an object of governance - commentary to Jones. Fennia 197(1) 141-144. https://doi.org/10.11143/fennia.80372

In this commentary, I reflect Rhys Jones' (in this issue) suggestion for geographers to take part in exploring and enabling the most effective governmental configurations for just futures. Starting from a Foucauldian perspective on governance as a problematizing activity, I bring to the fore that the future is not something that waits out there to be seized by rulers but a social and political construction dictated by the conditions of the present. Moreover, I also highlight that a conventional scalar framework is not sufficient for understanding complex networks of governance in an increasingly globalized policy world. Accordingly, in studying the future as an object of governance we need to be aware of the engagement of nationally/regionally situated policies with prevailing power relations which extend well beyond the territorial boundaries of governance and which regulate our capacities to imagine the future(s). This is of utmost importance for geographers entering the policy world.

Keywords: future, policy object, scale

Juho Luukkonen, RELATE Centre of Excellence, Department of Geosciences and Geography, PL 4 (Yliopistonkatu 3), University of Helsinki, Finland. E-mail: juho.luukkonen@helsinki.fi

In his article "Governing the future and the search for spatial justice: Wales' Well-being of Future Generations Act" Rhys Jones discusses the governing of the future from a geographical perspective. In the article Jones argues that there is a need for geographical studies since the governance of the future is an inherently spatial phenomenon which is "embedded in various ways in particular states, nations and regions" (Jones 2019, 9) and "played out across a series of connected geographical scales" (Jones 2019, 9).

Jones' remarks on the scalar structuration and embeddedness of governance illustrate nicely how ambiguous policy objects such as "future" and "spatial justice" are prone to competing interpretations and parochial usages. In this reflective response, I focus on four broader themes which in my opinion merit further attention. First, I discuss the becoming and invention of the "future" as an object of governance. Leaning on a Foucauldian reading of government as a problematizing activity, I argue that the future is not something that waits out there to be seized by rulers. Instead, it is a social and political construction dictated by the prevailing power relations and conditions of the present. In the second section, I focus on the scalar understanding of governance and discuss alternative ways of approaching governance in an increasingly transnational world of policy making. In the final section, I briefly comment on Jones' suggestion for geographers to take the leading role in exploring the impacts of geographies on the governance of more equal and just futures. 


\section{The invention of the "future" as an object of governance}

In his article, Jones (2019) notes that the future emerges as an indeterminate becoming which carries with it a wide range of more hopeful and just alternatives. However, throughout the paper he uses expressions such as the "governing the future" and "governance of the future" (emphasis added). While the definite article and the possessive preposition may be used for grammatical purposes only, the formulations prompt questions related to the essence and becoming of the "future" as a target of governmental activities.

In her recently published textbook on the post-World War II future politics and studies, Andersson $(2018,22)$ has noted that "the future is a product of the historical contingencies and power structures of the present that make certain conjectures possible and others not in distinct historical universes." Andersson's notion refers to a clichéd constructionist idea that the "future" is a political and social construction of the powerful. The argument is obvious for most scholars and an inadequate conclusion in itself. However, it is a good reminder that the future is not something that waits out there to be discovered and governed by genuine bureaucrats but is invented and made up in those very same governmental practices which seek to address it. Perhaps more importantly, her argument orients one to take a "present-as-reality" perspective on the construction of the future as an object of governance (e.g. Flockhart 2010). In other words, the future as a governmental object is inescapably bound by our present understandings and diagnostic capacities and is thus in a permanent process of reconstitution and reconstruction.

Seeing the future as a social and political construction, which is regulated by present structures and processes, resonates with Foucauldian policy studies which do not take policies as responses to selfevident problems but pay attention to the construction of policy objects and problems as an inherent feature of public policy processes (e.g. Rose 1999; Dikeç 2007). Broadly speaking these studies stem from the idea that government is "a problematizing activity... intrinsically linked to the problems around which it circulates" (Rose \& Miller 1992, 181). In other words, policy making is not only about reacting to perceived societal problems or challenges but an art of diagnostics which actively makes up its objects. The Foucauldian perspective on the production of the future as an object of governance and policy practices opens possibilities for scrutinizing the ways in which politicians, policy-makers and other stakeholders have contributed to the construction and reduction of the undetermined future(s) to a singular object of research and governmental activities. Furthermore, the perspective opens avenues for pondering how certain hegemonic ideologies, imaginaries, or modes of knowledge frame attempts to study and govern the future(s) in different geographical contexts. This perspective seems even more relevant in the light of the author's suggestion that geographers should take a more visible role in exploring the geographies of the future governance.

\section{Transnational spaces of governance}

In his article, Jones (2019) makes an important argument by stating that scale possesses consequences for the governance of the future. However, the discussion of the Well-being Act on three scales, national, local and individual, leaves aside the role and the implications of the international scale for the governance of Wales in general and for attempts to operationalize the national Well-being Act at the local scale and at the level of individual civil servants. As various studies on the geographies of governance and policy mobilities have noted, in an increasingly interconnected world policies are neither conducted within hierarchically arranged and vertically leveled "chains of command" nor within enclosed territorial arenas (e.g. Stone 2012; Temenos \& McCann 2013; Prince 2016; Moisio et al. 2018). Instead, practices of governance and policy-making occur in complex networks of actors which extend temporally and spatially well beyond the present and the jurisdictional boundaries of formal administrative structures. Accordingly, the framing of the future as an object of governance in Wales or elsewhere is not solely a "domestic matter" but essentially affected by international actors and trends.

The role of international policy networks in regulating domestic policies is not only a matter of academic interests but is essentially tied to the author's notion of spatial justice as the right and the 
possibility to take part in political life and in the governance of the future(s). The increased involvement of international actors in policy processes and the delegation of powers beyond democratically selected public bodies - such as consultancies and expert organizations - may lead to the narrowing down of the scope of alternative future paths and to a situation whereby the voices of relevant stakeholders are not heard in the envisioning of the desired national futures.

The emergence of the "urban" as an episteme of our time which sets "the condition of possibility for understanding major aspects of contemporary global economic, social and political life" (Brenner \& Schmid 2015, 155) offers an illustrative example of the narrowing down of the "public sphere" and of possibilities to engage in political life. In Finland, for instance, as in various other western societies, the "urban" has become a central spatial imaginary regulating the ways of how and by whom the future(s) of the country are addressed and envisioned in policy debates and public discussions. Despite the fact that urbanization is often articulated through the depoliticizing notions of "general interest" and "common good" as a nationally necessary project, it is a highly exclusive imaginary which not only leads potentially to spatially unjust futures but may also lead to spatially unjust governance arrangements as certain actors or localities are considered irrelevant stakeholders in the envisioning of the (urban) futures of the state (Luukkonen \& Sirviö forthcoming). In envisioning increased urbanization as an appropriate and necessary future vision for the country, politicians from the core urban regions have played an active and prominent role. Yet, the role of various international expert organizations (e.g. OECD, EU, WTO), well-known individual consultants and academic gurus has also been remarkable. Their recommendations and viewpoints have been used successfully in depoliticizing urban-centered national visions and in politicizing and marginalizing alternative non-urban future visions.

\section{Geography and governance - what role and for whom?}

In his concluding remarks, Jones (2019) suggests a more active role for geographers both in exploring the impacts of geographical themes on attempts to achieve spatial justice in the future and in enabling the most effective governmental configurations to be developed within specific geographical settings. The suggestion is a bit problematic as it bundles a vast set of very diverse "geographies-of-this-andthat" under a singular banner as if there was a peculiar overarching quality which qualifies all geographers to ponder the most effective governmental configurations within different geographical settings. If that is the case, what are the peculiar skills or capacities that justify geographers' role in the making of more just futures? Is it geographers' mythical virtue of understanding human-nature relations as promulgated in seminal disciplinary textbooks (e.g. Peet 1998)? Or is it rather our understanding of the inherent spatiality of human life?

While the answer lies probably closer to the latter option, it is worth accentuating that the capability to see the spatiality of things is not enough to make geographers experts on issues of governance. This is especially the case given that geographers' monopoly over the concept of space has been broken down as scholars across the social sciences - often better equipped to understanding governance and policy processes - have become increasingly aware of the inherent spatiality of social and political life (e.g. Gieryn 2000; Berezin \& Schain 2003).

The fact that understanding geographies of governance necessitates also other virtues than the "spatial gaze" leads to another crucial question: if only some of the geographers possess capabilities for taking a leading role, then who among us would/should they be? Some geographers - whose ontological and epistemological commitments probably resonate better with current political tastes than others or those who have been able to engage with "sexy" empirical issues - have already been able to get their voices heard. However, those scholars who operate in the margins of geography, with marginal topics or against the prevailing political fashion may confront difficulties in finding their ways to the arenas where the future(s) are formulated and governed. The third crucial issue which is worth reflecting on is the double hermeneutic role of social sciences. This refers to the idea that as researchers, we are not only observing social reality from a distance but simultaneously contributing actively to the construction of the world (Giddens 1987).

Altogether, we need to be aware of the prevailing power relations, hegemonic ideologies, imaginaries, sedimented thoughts, and knowledges that guide and regulate our possibilities to think 
of the future(s) as well as of the consequences of our research practices and outputs in delimiting potential future avenues (cf. Beaumont et al. 2005). History is fraught with examples of how the too intimate fraternization of scholars with the rulers has led to the blunting of the critical and analytical bite of research (see Peck 2016). In the most extreme cases consequences have been anything but just (see Barnes \& Minca 2013).

\section{References}

Andersson, J. (2018) The Future of the World: Futurology, Futurists, and the Struggle for the Post-Cold War Imagination. Oxford University Press, Oxford.

Barnes, T. J. \& Minca, C. (2013) Nazi spatial theory: the dark geographies of Carl Schmitt and Walter Christaller. Annals of the Association of American Geographers 103(3) 669-687. https://doi.org/10.1 $\underline{080 / 00045608.2011 .653732}$

Beaumont, J., Loopmans, M. \& Uitermark, J. (2005) Politicization of research and the relevance of geography: some experiences and reflections for an ongoing debate. Area 37(1) 118-126. https:// doi.org/10.1111/j.1475-4762.2005.00606.x

Berezin, M. \& Schain, M. (2003) (eds.) Europe Without Borders: Remapping Territory, Citizenship and Identity in a Transnational Age. Johns Hopkins University Press, Baltimore.

Brenner, N. \& Schmid, C. (2015) Towards a new epistemology of the urban? City 19(2-3) 151-182. https://doi.org/10.1080/13604813.2015.1014712

Dikeç, M. (2007) Space, governmentality, and the geographies of French urban policy. European Urban and Regional Studies 14(4) 277-289. https://doi.org/10.1177/0969776407081162

Flockhart, T. (2010) Europeanization or EU-ization? The transfer of European norms across time and space. Journal of Common Market Studies 48(4) 787-810. http://doi. org/10.1111/j.1468-5965.2010.02074.x

Giddens, A. (1987) Social Theory and Modern Sociology. Stanford University Press, Palo Alto.

Gieryn, T. F. (2000) A space for place in sociology. Annual Review of Sociology 26(1) 463-496. https:// doi.org/10.1146/annurev.soc.26.1.463

Jones, R. (2019) Governing the future and the search for spatial justice: Wales' Well-being of Future Generations Act. Fennia 197(1) 8-24. https://doi.org/10.11143/fennia.77781

Luukkonen, J. \& Sirviö, H. (forthcoming) Politics of depoliticization and the constitution of cityregionalism as a dominant spatial-political imaginary in Finland.

Moisio, S., Luukkonen, J. \& Jonas, A. E. G. (2018) Political geographies of globalization. In Kloosterman, R. C., Mamadouh, V. \& Terhorst, P. (eds.) Handbook on the Geographies of Globalization, 135-147. Edward Elgar Publishing, Cheltenham. https://doi.org/10.4337/9781785363849.00018

Peck, J. (2016) Economic rationality meets celebrity urbanology: exploring Edward Glaeser's city. International Journal of Urban and Regional Research 40(1) 1-30. https://doi.org/10.1111/1468$\underline{2427.12321}$

Peet, R. (1998) Modern Geographical Thought. Blackwell Publishers, Oxford.

Prince, R. (2016) The spaces in between: mobile policy and the topographies and topologies of the technocracy. Environment and Planning D: Society and Space 34(3) 420-437. https://doi. org/10.1177/0263775815618401

Rose, N. (1999) Powers of Freedom: Reframing Political Thought. Cambridge University Press, Cambridge and New York. https://doi.org/10.1017/CBO9780511488856

Rose, N. \& Miller, P. (1992) Political power beyond the state-problematics of government. British Journal of Sociology 43(2) 173-205. https://doi.org/10.2307/591464

Stone, D. (2012) Transfer and translation of policy. Policy Studies 33(6) 483-499. https://doi.org/10.10 $\underline{80 / 01442872.2012 .695933}$

Temenos, C. \& McCann, E. (2013) Geographies of policy mobilities. Geography Compass 7(5) 344-357. https://doi.org/10.1111/gec3.12063 